\title{
EFFECT OF THE DESIGNING MOBILE APPLICATIONS ON SMARTPHONE TO CUSTOMER DEMANDING: CASE STUDY OF THE CONCEPT OF UX UI
}

\author{
${ }^{1}$ Pibool Waijittragum \\ ${ }^{1}$ Suan Sunandha Rajabhat University. Email: pibool.wa@ssru.ac.th
}

\begin{abstract}
The popularity of digital devices especially smart phones has been dramatically increased with the innovation in technology from the past few years. The popularity of smart phones is based on the number of mobile applications that are designed for various purposes. The usage behavior of these mobile applications has many determinants that can shape the usage behavior regarding the mobile applications. In this context, the current study has been conducted in order to find out and explore the impact casted by need for uniqueness, self identity and perceived performance risk on the usage behavior of mobile application along with the mediating role of attitude towards design of mobile application. For this purpose, data from 447 mobile application designers has been collected through online survey questionnaire. The collected data has been analyzed through SPSS and AMOS statistically. The results of the study suggest that all the independent variables i.e. need for uniqueness; self identity and perceived performance risk have significant and positive impact on the usage behavior of mobile applications. In addition, the mediating role of attitude towards mobile application design has also been found as significant in all three cases.
\end{abstract}

Keywords: Need for Uniqueness, Self Identity, Perceived Performance Risk, Usage Behavior, Attitude, Mobile Application Article Received: 18 October 2020, Revised: 3 November 2020, Accepted: 24 December 2020

\section{Introduction}

In the past few years, the popularity of digital devices especially smart phones has been dramatically increased with the innovation in technology. The popularity of smart phones is based on the number of mobile applications that are designed for various purposes (Wang et al., 2018). According to statistics, the number of downloads of application from Google Play till May 2016 has exceeded 65 billion which shows the increased interest of people in these applications. In different smart phones, different apps are already installed such as App Store is installed in iOS, Play Store in Android phones etc. These already installed apps help the users search and find a variety of different apps designed for different purposes. These apps include games as well as other functions such as photo editing, music downloading, video players and the list is long. Another statistics have shown that till January 2016, the number of apps on Google Play has exceeded two million (Li et al.,
2017). This increased popularity of smart phones and mobile applications demands the study of usage behavior of these apps. These behaviors include what apps are demanded by the people and when is the demand of which app. All these aspects are studied in usage behavior. This provides useful information to the app developers in different contexts. Need of uniqueness involves the desire of a person to be different from others and in the current study this concept revolves around the uniqueness of the design of mobile applications. In the same way, self identity is the concept that refers to the perception of a person about himself/herself. There is a risk called as perceived performance risk that refers to the risk that the product might not be what it was perceived by the consumer. All these aspects i.e. need for uniqueness, self identity and perceived performance risk impact the usage behavior in one way or the other (Hu et al., 2016; Sarkar et al., 2016). 


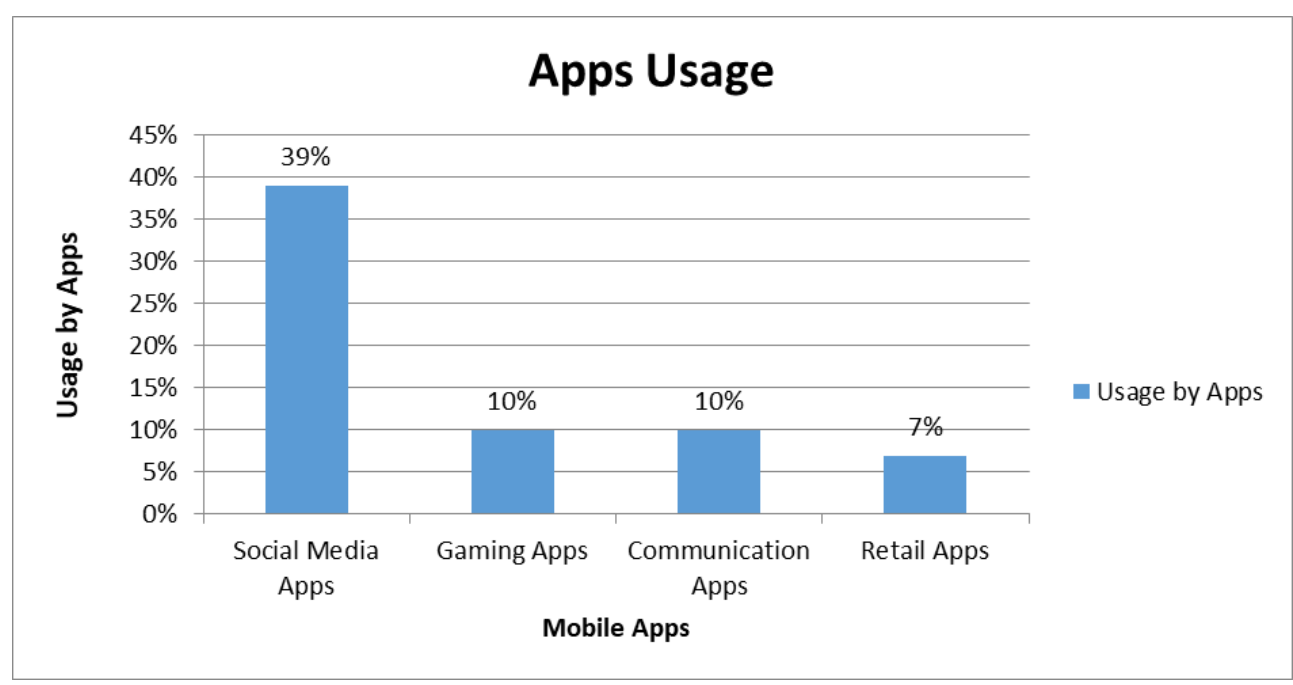

Figure 1: Mobile Apps Usage (themenifest.com)

In the past, there are various studies that have explored the different angles of mobile apps design and a very few studies have investigated the attitude and usage behavior towards the mobile application design. However, there is no study that has related the concepts such as need for uniqueness, self identity and perceived performance risk with the attitude and behavior towards mobile applications. Therefore this study has been conducted with the recommendation of Matthews, Rothenberg, and Gopalakrishnan (2019). The major objectives of the study are as follows:

- To analyze the impact of need for uniqueness on usage behavior of mobile application

- To analyze the impact of self identity on usage behavior of mobile application
- To analyze the impact of perceived performance risk on usage behavior of mobile application

- To determine the significant mediating impact of attitude towards design of mobile application on the relationship between need for uniqueness, self identity and perceived performance risk; and usage behavior of mobile application

This study will be very beneficial for the mobile application developers as they will get information about how different perceptions of the consumers impact the usage behavior for mobile application and they will be able to design the mobile applications accordingly. This will also result in the satisfaction of the consumers.

Table 1: \% of users of Mobile Applications (businessofapps.com)

\begin{tabular}{lc}
\hline Type of Application & \% of Users \\
\hline Social Media & $67 \%$ \\
Shopping & $56 \%$ \\
Games & $50 \%$ \\
Music Audio & $50 \%$ \\
Video Streaming & $40 \%$ \\
Current Affairs & $36 \%$ \\
Sport & $25 \%$ \\
Health and Fitness & $24 \%$ \\
\hline
\end{tabular}




\section{Literature Review}

\subsection{Impact of Need for Uniqueness on Usage Behavior of Mobile Application}

As discussed earlier, need for uniqueness is actually the characteristic of the consumer through which he/she wants to feel or acquire different things as compared to the other people. In other words, a person who wants to be distinct from each other and perceives it as a need is said to have the need for uniqueness. The studies have indicated that the people that have high sense of innovation in any field such as fashion are found to have higher need for uniqueness. Such results have been presented by Workman and Kidd (2000) in a related research. Other studies have discussed that the need for uniqueness in people derive the behavior in them regarding the choice of a product or service that is unique, different and innovative as compared to others. The concept of need for uniqueness is also supported by a theory named as theory of uniqueness (Abd, Khatibi, \& Ferdous, 2018; Abdul-Kahar, Ebi, \& Nasser, 2019; Abdul Aziz \& Abdul Manab, 2020; Adediyan, 2019; Adekoya, Olaoye, \& Lawal, 2020; Afroze \& Salehin, 2020; Afzal, Ejaz, \& Ahmad, 2019; Al Ahad, Khan, \& Rahman, 2020; Al Hussaini, 2019; Kauppinen-Räisänen, Björk, Lönnström, \& Jauffret, 2018; Lang \& Armstrong, 2018). This theory revolves around the idea that how the need for uniqueness might impact the choice of the consumers in different sectors and in the case of current study, the context of mobile phone applications must be considered. The consumers will show a particular behavior by the usage of a mobile application that is developed on the basis of need for uniqueness. Thus, it can be hypothesized that;

H 1: Need for uniqueness has significant impact on usage behavior of mobile application

\subsection{Impact of Self Identity on Usage Behavior of Mobile Application}

The concept of self identity has been defined earlier and it refers to the way in which a person perceives his or her own being (Razzaq, Maqbool, \& Hameed, 2019; K.-P. Wiedmann, Hennigs, \&
Siebels, 2007). In the past literature, different researchers have studied thus concept in various contexts. For instance, the concept of self identity has been studied in relation with the idea of self concept. According to self concept, there are certain characteristics or properties that are associated with a person as per his or her perception or assumption (Hustvedt \& Dickson, 2009). The previous studies have made it quite clear that the consumers purchase those products that are aligned with their self concept or self identity. In other words, the products chosen by the consumers are associated with the personal characteristics of a person or reflect those characteristics (Sirgy, 1982; Tung, Koenig, \& Chen, 2017). In this way, the concept of self identity is associated with the consumer behavior or usage behavior. In this context, a study was conducted with respect to the environmental behaviors of consumers. The objective of the study was to find out whether the people that have the self identity of green environment or environmental friendliness have any impact on their purchase behavior of electric car or not (Barbarossa, De Pelsmacker, \& Moons, 2017). The results obtained by the study suggested that the people that show the green self identity nature consider their values more important (M. F. Chen, 2020; Jiang et al., 2016). Thus it can be suggested that the mobile applications that are developed or designed on the basis of self identity concept might shape the usage behavior of the consumers. The following hypothesis can be drawn thus;

H 2: Self Identity has significant impact on usage behavior of mobile application

\subsection{Impact of Perceived Performance Risk on Usage Behavior of Mobile Application}

The notion of perceived performance risk revolves around the idea that the product or service might not be on that level that was perceived or assumed by the consumer (Derbaix, 1983). This notion is directly or indirectly linked with the designing of mobile applications because there might always be a risk that the designed application is not up to the consumers' perceptions. These risks may be of 
different nature such as financial risk, social risk, performance risk etc. A study was conducted in this context in which the notion of perceived performance risk was studied in association with the promotion strategies such as discounts etc. The moderating impact of this risk was found as significant in that study (Lowe, 2010). In another related study, it was found out that the level of performance risk is much higher in the technology related products and in the context of current study, mobile application designing might also involve some performance risk (Khan \& Ahmad, 2016; Parry, Sarma, \& Yang, 2020). They further suggested that the performance and financial risks are the major risks that are associated with the customization of the products. In the current study, this relationship will be studied in context of the usage behavior of mobile applications. This discussion may lead to the following hypothesis:

H 3: Perceived performance risk has significant impact on usage behavior of mobile application

\subsection{Mediating Impact of Attitude towards Design of Mobile Application}

As far as attitude is concerned, it refers to the idea of the evaluative reaction about some product or service received. Such types of reactions are associated with the values, beliefs and norms of the people that they react to certain products or services in a particular way. There is a related theory names as theory of reasoned action. This theory revolves around the fact that the attitude of an individual about some product is an essential factor to determine the behavior or usage behavior of that product (Azjen, 1980). This theory is a traditional theory related to psychology and the intended conscious behaviors are studied in it. In addition, this theory also suggests that the consumers or people are rational and they will always consider the results of their actions before they perform a certain behavior. The consumer behavior or the current context of the study i.e. usage behavior is generally studied with the support of this particular theory. In context of usage behavior, a study was conducted in the past whose objective was to study the usage behavior of mobile phone apps by collecting data through the IP level traces from the network provider (Xu et al., 2011). Another similar study was conducted with the motive to study the mobile phone apps usage behavior through network traffic. The basis on the analysis of the study was app popularity and the distributions related to downloads. The results suggested that the download distribution in different mobile systems such as iOS and Android are completely different from each other based on the settings of the system (Li et al., 2017). Thus it can be suggested on the basis of past literature that attitudes regarding the designing of mobile apps and the usage behaviors associated with it can be related (S. Lee, 2017; Sinha \& Verma, 2018). Thus the following hypotheses can be generated:

H 4(a): Attitude towards design of mobile application has significant mediating impact on the relation between need for uniqueness and usage behavior of mobile applications

H 4(b): Attitude towards design of mobile application has significant mediating impact on the relation between self identity and usage behavior of mobile applications

H 4(c): Attitude towards design of mobile application has significant mediating impact on the relation between perceived performance risk and usage behavior of mobile applications

\subsection{Theoretical Framework}




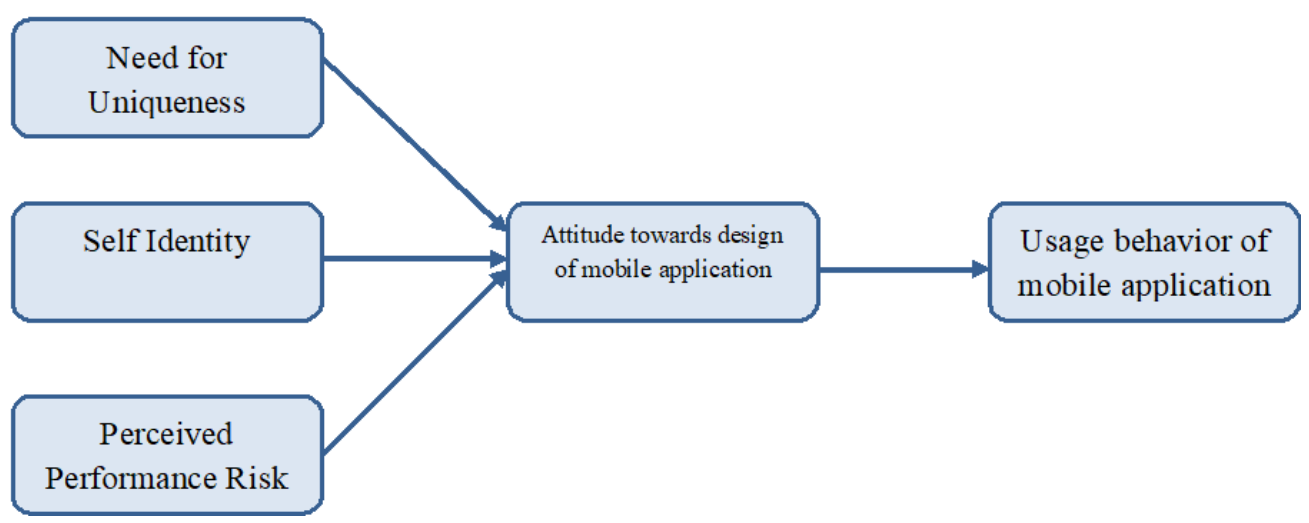

\section{Methodology}

In this section, the researcher has discussed the data collection process and sampling in detail followed by the discussion on the measurement items of the variables. The data analysis techniques used in the study have also been mentioned.

\subsection{Samples and Data Collection}

The motive behind the current study was to find out and explore the impact casted by need for uniqueness, self identity and perceived performance risk on the usage behavior of mobile application along with the mediating role of attitude towards design of mobile application. As the current study has been conducted in context of the usage behavior of mobile applications, therefore, the most suited respondents for the study were the mobile application developers who were working with different organizations in the research area. For data collection purpose, online questionnaires were distributed among them after contacting with them and taking time through purposive sampling technique. In this regard, 500 questionnaires were distributed among the potential respondents and after the collecting back of the filled questionnaires, only 447 were considered to be used in the study. The remaining responses were discarded due to their incompletion or unreliability.

\subsection{Measures}

All these variables have been measured through various measurement items that have been discussed here. Need for uniqueness has been measured through seven measurement items, one of which is 'I'm often on the lookout for new mobile applications that will add to my personal uniqueness" (Bian \& Forsythe, 2012). In the similar manner, self identity has been measured by three measurement items, one of which is "I often try to avoid mobile applications that I know are used by the general population" (K. P. Wiedmann, Hennigs, \& Siebels, 2009). Moreover, perceived performance risk has been measured by using eight measurement items, one of which is "I'm not certain whether I can get the mobile applications that I want" (H.-H. Lee \& Moon, 2015). Usage behavior of mobile application is the dependent variable and the researcher has measured it with three measurement items, developed in a past study. A sample item is "How frequently do you use mobile applications" (Moon \& Kim, 2001). In the last, attitude towards design of mobile application is the mediating variable, measured through six items, obtained form a past study. One of these items is "I can sort out my feelings via these mobile applications" (Taylor \& Todd, 1995). These items are measured on the five point Likert scale that ranges from 1 to 5 . The collected data has been statistically analyzed using SPSS and AMOS.

\section{Data Analysis}

\subsection{Demographics}

The demographic data in terms of gender indicate that there are 55.3 percent of males and 44.7 percent females among the respondents. In case of age, it is evident that most of the respondents i.e. 43 percent were having the age from 25 to 35 years and only 3.6 percent were having age more than 45 years. As far as experience is concerned, most of the respondents i.e. 43.4 percent were having the experience of 2 to 5 years in the organizations. 
These demographics provide basic information about the respondents.

\subsection{Descriptive Statistics}

Table 1 presents the descriptive statistics of the variables of the study and it is clear from the table that the data is free from any outlier as the minimum and maximum values range from 1 to 5 . In addition, the skewness values also provide enough evidence of the normality of the collected data.

Table 2: Descriptive Statistics

\begin{tabular}{|c|c|c|c|c|c|c|c|c|}
\hline & & & \multirow{2}{*}{$\begin{array}{c}\text { Minimu } \\
\mathrm{m}\end{array}$} & \multirow{2}{*}{$\begin{array}{l}\text { Maximu } \\
\text { m }\end{array}$} & \multicolumn{4}{|c|}{ Std. } \\
\hline & & $\mathrm{N}$ & & & Mean & Deviation & \multicolumn{2}{|c|}{ Skewness } \\
\hline & & Statistic & Statistic & Statistic & Statistic & Statistic & Statistic & Std. Error \\
\hline AttTDMA & & 447 & 1.00 & 5.00 & 3.1902 & 1.04817 & -.162 & .115 \\
\hline NeedUniq & & 447 & 1.00 & 5.00 & 3.3503 & 1.00994 & -.334 & .115 \\
\hline PPerfRisk & & 447 & 1.00 & 5.00 & 3.5066 & 1.17146 & -.534 & .115 \\
\hline SlefEdent & & 447 & 1.00 & 5.28 & 3.4134 & 1.15388 & -.508 & .115 \\
\hline UsBeMAp & & 447 & 1.00 & 5.00 & 3.5518 & 1.15151 & -.557 & .115 \\
\hline $\begin{array}{l}\text { Valid } \\
\text { (listwise) }\end{array}$ & $\mathrm{N}$ & 447 & & & & & & \\
\hline
\end{tabular}

\subsection{KMO and Bartlett's Test}

The table 2 shows the results of KMO and Bartlett's test and the results of both these tests are in favor of the usefulness of factor analysis in the study and for the adequacy of the responses. The KMO test value being close to 1 and the Bartlett's test value being lower than 0.05 provides enough evidence for it.

Table 3: KMO and Bartlett's Test

\begin{tabular}{lrr}
\hline Kaiser-Meyer-Olkin Measure of Sampling Adequacy. & .944 \\
Bartlett's Test of Sphericity & Approx. Chi-Square & 13617.886 \\
& df & 351 \\
& Sig. & .000 \\
\hline
\end{tabular}

\subsection{Rotated Component Matrix}

The results of rotated component matrix presented in table 3 show that the factor loadings associated with all the items of the variables are greater than
0.7 which is enough evidence to show that these factors are contributing to the variable and in the current study.

Table 4: Rotated Component Matrix ${ }^{\mathrm{a}}$

\begin{tabular}{lrrrr}
\hline & \multicolumn{3}{c}{ Component } \\
\cline { 2 - 5 } & 1 & 2 & & 4 \\
\hline AM1 & & .816 & \\
AM2 & & & .862 & \\
AM3 & & .814 & \\
AM4 & & .770 & \\
AM5 & & & .806 & \\
AM6 & & & .836 & \\
NU1 & & & \\
NU2 & & & \\
NU3 & & .748 & & \\
NU4 & & .727 & &
\end{tabular}


NU5

NU6

NU7

PR1

PR2

PR3

PR4

PR5

PR6

PR7

PR8

SE1

SE2

SE3

UB1

UB2

UB3
.818

.871

.821

\subsection{Convergent and Discriminant Validity}

The results for two types of construct validities i.e. convergent and discriminant validity have been presented in table 4 according to which it is clear
.839

.854

.840

.827

.839

.855

Table 5: Convergent and Discriminant Validity

\begin{tabular}{lrrrrrrrr}
\hline & \multicolumn{1}{c}{ CR } & AVE & MSV & SE & AM & NU & PR & UB \\
\hline SE & 0.928 & 0.810 & 0.295 & $\mathbf{0 . 9 0 0}$ & & & & \\
AM & 0.945 & 0.741 & 0.323 & 0.461 & $\mathbf{0 . 8 6 1}$ & & & \\
NU & 0.945 & 0.711 & 0.323 & 0.451 & 0.568 & $\mathbf{0 . 8 4 3}$ & & \\
PR & 0.916 & 0.837 & 0.295 & 0.543 & 0.468 & 0.455 & $\mathbf{0 . 9 1 5}$ & \\
UB & 0.912 & 0.776 & 0.278 & 0.384 & 0.472 & 0.527 & 0.449 & $\mathbf{0 . 8 8 1}$ \\
\hline
\end{tabular}

\subsection{Confirmatory Factor Analysis}

The results of confirmatory factor analysis CFA have been reported in table 5 according to which the various indicators of CFA such as CMIN/DF, GFI, CFI, IFI, RMSEA etc. are exactly within the that all the measurement items are actually measuring a particular variable of the study. This makes the data eligible to move for further analysis.

Table 6: Model Fit Indices

\begin{tabular}{lccccc}
\hline CFA Indicators & CMIN/DF & GFI & IFI & CFI & RMSEA \\
\hline Threshold Value & $\leq 3$ & $\geq 0.80$ & $\geq 0.90$ & $\geq 0.90$ & $\leq 0.08$ \\
Observed Value & 2.555 & 0.875 & 0.964 & 0.964 & 0.059 \\
\hline
\end{tabular}

Figure 2: CFA 


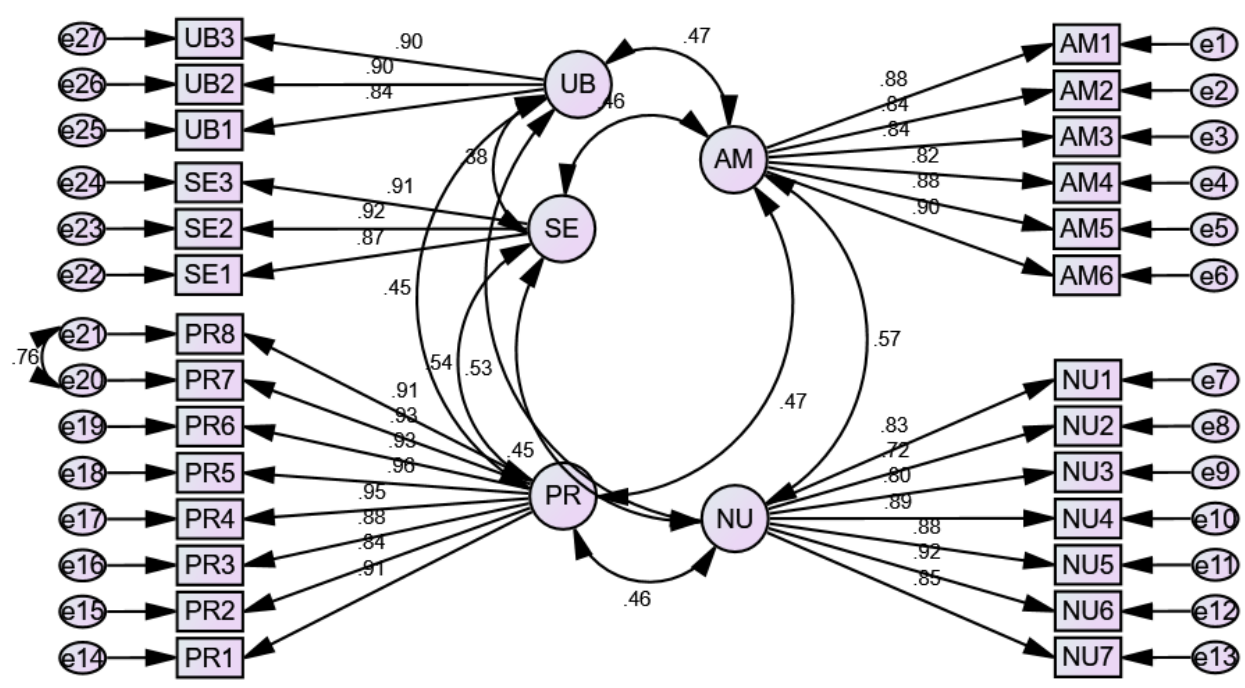

\subsection{Structural Equation Modeling}

The results of SEM given in the table 6 suggest that all the independent variables i.e. need for uniqueness; self identity and perceived performance risk have significant and positive impact on the usage behavior of mobile applications. In addition, the mediating role of attitude towards mobile application design has also been found as significant in all three cases.

Table 7: Structural Equation Modeling

\begin{tabular}{ccccc}
\hline Total Effect & PPerfRisk & SlefEdent & NeedUniq & AttTDMA \\
\hline AttTDMA & $.164^{* *}$ & $.188^{* *}$ & $.412^{* *}$ & .000 \\
\hline UsBeMAp & $.194^{* *}$ & $.146^{* *}$ & $.353^{* *}$ & $.128^{*}$ \\
\hline Direct Effect & PPerfRisk & SlefEdent & NeedUniq & AttTDMA \\
\hline AttTDMA & $.164^{* *}$ & $.188^{* *}$ & $.412^{* *}$ & .000 \\
\hline UsBeMAp & $.173^{* *}$ & $.121^{* *}$ & $.301^{* *}$ & $.128^{*}$ \\
\hline Indirect Effect & PPerfRisk & SlefEdent & NeedUniq & AttTDMA \\
\hline AttTDMA & .000 & .000 & .000 & .000 \\
\hline UsBeMAp & $.021^{*}$ & $.024^{*}$ & $.053^{*}$ & .000 \\
\hline
\end{tabular}

Figure 3: SEM

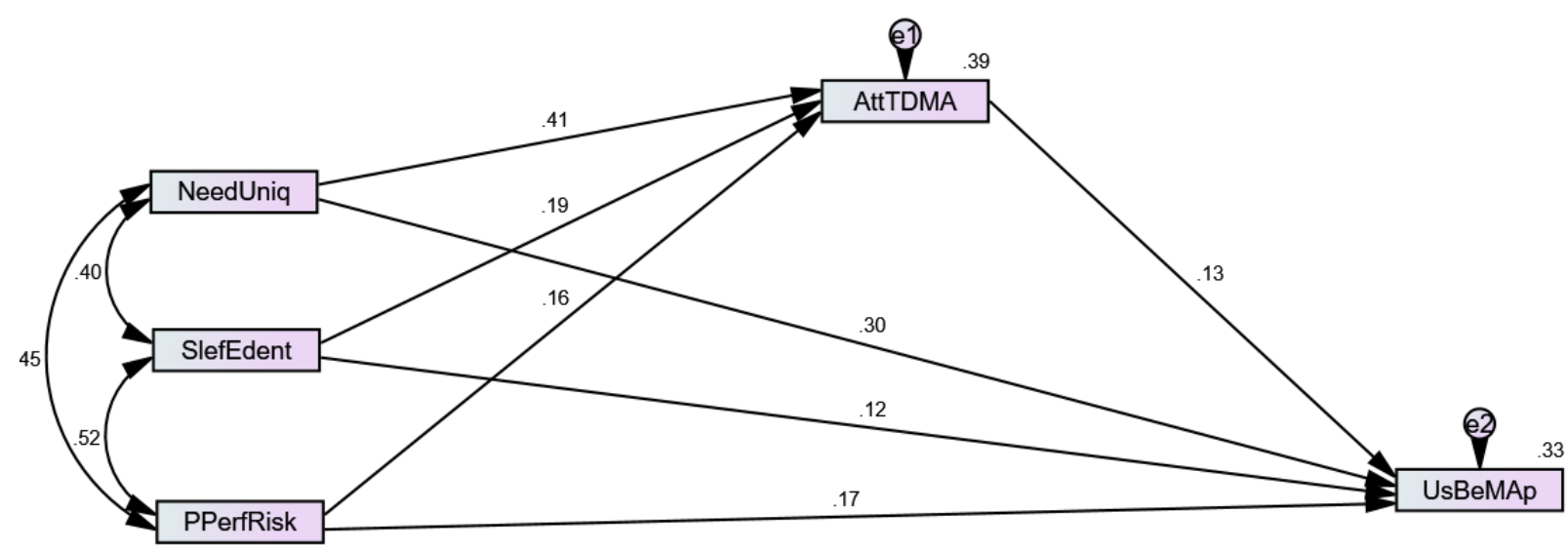




\section{Discussion and Conclusion}

\subsection{Discussion}

This study was aimed to explore the impact casted by need for uniqueness, self identity and perceived performance risk on the usage behavior of mobile applications with the mediating role of attitude towards mobile application designing. To fulfill this objective, the researcher reviewed the literature and came up with the hypotheses based on the literature review. These hypotheses have been tested and verified using different tools and the results obtained have been discussed here. The first hypothesis that need for uniqueness has significant impact on usage behavior of mobile applications has been accepted as the impact of need of uniqueness has been found significant on usage behavior. The usage behavior of the user of a mobile phone application is supposed to be shaped according to his or her idea or concept of being different from others. This result is in accordance with the similar past studies (Imhoff \& Lamberty, 2017; Tseng \& Balabanis, 2017). The next hypotheses that self identity has significant impact on usage behavior of mobile applications has also been accepted based on the result that self identity has significant impact on usage behavior. The usage behavior of a mobile phone application user is supposed to be consistent with the idea of a person of how he or she feels about himself of herself. This result is also in consistency with the past literature (Johe \& Bhullar, 2016; Pan, Lu, Wang, \& Chau, 2017). The third hypothesis that perceived performance risk has significant impact on usage behavior of mobile application has also been accepted as per the results. If there is a persistent feeling of risk in the user's mind, it will alter the usage behavior. The similar studies from the past have shown such results (Y.-S. Chen \& Huang, 2017; Kumar \& Bajaj, 2019). In the last, hypotheses were generated based on the mediating impact of attitude towards design of mobile application and these hypotheses were also accepted as its mediating impact was found significant for all the variables which is consistent with the past studies (Mathur \& Chetty, 2017; Oyelere, Suhonen, Wajiga, \& Sutinen, 2018).

\subsection{Conclusion}

The detailed analysis of the collected data from the respondents by using different statistic tools and techniques has lead to the results obtained for the study. As the impact of all the independent variables i.e. need for uniqueness; self identity and perceived performance risk has been found significant on the usage behavior of mobile applications, it can be concluded that different perceptions of the consumers impact the usage behavior for mobile application and thus the mobile applications developers must design the mobile applications accordingly.

\subsection{Implications and Limitations}

The theoretical implication of the study is that it contains the literature and information about the consumers' different perceptions and their impact on the usage behavior. This information might be helpful for the researchers to be used in their studies. Practically this study will provide information to the mobile application developers that different perceptions of the consumers impact the usage behavior for mobile application and thus the mobile applications developers must design the mobile applications accordingly.

The sample size of the study might be increased and more variables regarding the perceptions of the consumers might be added. The study may be conducted in the context of some other sector or industry as well.

\section{REFERENCES}

[1] Abd, J., Khatibi, A., \& Ferdous, S. (2018). The impact of scientific epistemological beliefs of Sri Lankan senior secondary students on their approaches to learning science: A structural equation modelling analysis. Asian Journal of Contemporary Education, 2(2), 60-69. doi: 10.18488/journal.137.2018.22.60.69

[2] Abdul-Kahar, A., Ebi, S. B. S., \& Nasser, S. M. A. (2019). Conceptualisation of lack of discipline and probity as the main cause towards good governance practice. International Journal of Public Policy and Administration Research, 6(1), 12-22. 
[3] Abdul Aziz, N. A., \& Abdul Manab, N. (2020). Does risk culture matter for sustaining the business? evidence from Malaysian environmentally sensitive listed companies. International Journal of Management and Sustainability, 9(2), 91100.

doi:

10.18488/journal.11.2020.92.91.100

[4] Adediyan, A. R. (2019). Public saving, a social vice: Is keynes right? Sub-Saharan Africa economic growth in perspective. Asian Development Policy Review, 7(4), 297-306. doi: 10.18488/journal.107.2019.74.297.306

[5] Adekoya, A. A., Olaoye, A. S., \& Lawal, A. B. (2020). Informal Sector and Tax Compliance in Nigeria-Challenges and Opportunities. International Journal of Emerging Trends in Social Sciences, 8(2), 57-69.

doi: https://doi.org/10.33094/8.2017.2020.61.3 0.41

[6] Afroze, D., \& Salehin, M. R. U. (2020). Efficiency of microfinance (MF) institutions in Bangladesh: A study on top $10 \mathrm{MF}$ institutions. International Journal of Business, Economics and Management, 7(2), 120-130. DOI:, 7(2), 120-130. doi: 10.18488/journal.62.2020.72.120.130

[7] Afzal, M., Ejaz, S., \& Ahmad, S. (2019). Analysis of domestic versus foreign banks efficiency in Pakistan. Asian Journal of Economics and Empirical Research, 6(1), 36-44.

doi: https://doi.org/10.20448/journal.501.2019. 61.36.44

[8] Al Ahad, A., Khan, M. R., \& Rahman, M. S. (2020). HR retention strategies for enhanced job satisfaction in a highly competitive job market: A study with private banking sector in Bangladesh. International Journal of Social Sciences Perspectives, 6(1), 53-58. doi: https://doi.org/10.33094/7.2017.2020.61.5 3.58
[9] Al Hussaini, A. N. (2019). Credit risk and financial stability under controlling effect of financial sector development: A study from banking sector of gcc members. International Journal of Asian Social Science, $9(1), \quad 122-138 . \quad$ doi: 10.18488/journal.1.2019.91.122.138

[10] Azjen, I. (1980). Understanding attitudes and predicting social behavior. Englewood Cliffs.

[11] Barbarossa, C., De Pelsmacker, P., \& Moons, I. (2017). Personal values, green self-identity and electric car adoption. Ecological Economics, 140, 190-200.

[12] Bian, Q., \& Forsythe, S. (2012). Purchase intention for luxury brands: A cross cultural comparison. Journal of Business Research, 65(10), 1443-1451.

[13] Chen, M. F. (2020). The impacts of perceived moral obligation and sustainability self-identity on sustainability development: A theory of planned behavior purchase intention model of sustainabilitylabeled coffee and the moderating effect of climate change skepticism. Business Strategy and the Environment.

[14] Chen, Y.-S., \& Huang, S. Y. (2017). The effect of task-technology fit on purchase intention: The moderating role of perceived risks. Journal of Risk Research, 20(11), 1418-1438.

[15] Derbaix, C. (1983). Perceived risk and risk relievers: An empirical investigation. Journal of economic psychology, 3(1), 1938.

[16] Hameed, W. U., Basheer, M. F., Iqbal, J., Anwar, A., \& Ahmad, H. K. (2018). Determinants of Firm's open innovation performance and the role of $R \& D$ department: an empirical evidence from Malaysian SME's. Journal of Global Entrepreneurship Research, 8(1), 29. doi: https://doi.org/10.1186/s40497-018-01128

[17] Hu, W., Gao, Y., Ha, K., Wang, J., Amos, B., Chen, Z., . . . Satyanarayanan, M. 
(2016). Quantifying the impact of edge computing on mobile applications. Paper presented at the Proceedings of the 7th ACM SIGOPS Asia-Pacific Workshop on Systems.

[18] Hustvedt, G., \& Dickson, M. A. (2009). Consumer likelihood of purchasing organic cotton apparel. Journal of Fashion Marketing and Management: An International Journal.

[19] Imhoff, R., \& Lamberty, P. K. (2017). Too special to be duped: Need for uniqueness motivates conspiracy beliefs. European Journal of Social Psychology, 47(6), 724734.

[20] Jiang, C., Zhao, W., Sun, X., Zhang, K., Zheng, R., \& Qu, W. (2016). The effects of the self and social identity on the intention to microblog: An extension of the theory of planned behavior. Computers in Human Behavior, 64, 754-759.

[21] Johe, M. H., \& Bhullar, N. (2016). To buy or not to buy: The roles of self-identity, attitudes, perceived behavioral control and norms in organic consumerism. Ecological Economics, 128, 99-105.

[22] Kauppinen-Räisänen, H., Björk, P., Lönnström, A., \& Jauffret, M.-N. (2018). How consumers' need for uniqueness, selfmonitoring, and social identity affect their choices when luxury brands visually shout versus whisper. Journal of Business Research, 84, 72-81.

[23] Khan, M. M., \& Ahmad, S. A. (2016). Moderation of online consumers'review on relationship between perceived risk and consumers'unwillingness to buy home appliances online. Paradigms, 10(2), 26.

[24] Kumar, P., \& Bajaj, R. (2019). Exploring the influence of demographic factors on perceived performance risk among youth towards online shopping in Punjab. International Journal of Business and Globalisation, 23(1), 47-68.

[25] Lang, C., \& Armstrong, C. M. J. (2018). Collaborative consumption: The influence of fashion leadership, need for uniqueness, and materialism on female consumers' adoption of clothing renting and swapping. Sustainable Production and Consumption, 13, 37-47.

[26] Lee, H.-H., \& Moon, H. (2015). Perceived risk of online apparel mass customization: Scale development and validation. Clothing and Textiles Research Journal, 33(2), 115128.

[27] Lee, S. (2017). Evaluation of Mobile Application in User's Perspective: Case of P2P Lending Apps in FinTech Industry. TIIS, 11(2), 1105-1117.

[28] Li, X., Zheng, C., Zhang, C., Li, S., Guo, L., \& Xu, J. (2017). Understanding usage behaviors of mobile apps by identifying app package in network traffic. Paper presented at the 2017 IEEE 9th International Conference on Communication Software and Networks (ICCSN).

[29] Lowe, B. (2010). Consumer perceptions of extra free product promotions and discounts: the moderating role of perceived performance risk. Journal of Product and Brand management, 19(7), 496-503.

[30] Mathur, A., \& Chetty, M. (2017). Impact of user characteristics on attitudes towards automatic mobile application updates. Paper presented at the Thirteenth Symposium on Usable Privacy and Security (\{SOUPS $\}$ 2017).

[31] Matthews, D., Rothenberg, L., \& Gopalakrishnan, S. (2019). The impact of mass customization on fashion-innovative students: an assessment of need for uniqueness, self-identity, and perceived performance risk. International Journal of Fashion Design, Technology and Education, 12(3), 293-300.

[32] Moon, J.-W., \& Kim, Y.-G. (2001). Extending the TAM for a World-WideWeb context. Information \& management, 38(4), 217-230.

[33] Oyelere, S. S., Suhonen, J., Wajiga, G. M., \& Sutinen, E. (2018). Design, development, 
and evaluation of a mobile learning application for computing education. Education and Information Technologies, 23(1), 467-495.

[34] Pan, Z., Lu, Y., Wang, B., \& Chau, P. Y. (2017). Who do you think you are? Common and differential effects of social self-identity on social media usage. Journal of Management Information Systems, 34(1), 71-101.

[35] Parry, M. E., Sarma, S., \& Yang, X. (2020). The Relationships among Dimensions of Perceived Risk and the Switching Intentions of Pioneer Adopters in Japan. Journal of International Consumer Marketing, 1-20.

[36] Razzaq, S., Maqbool, N., \& Hameed, W. U. (2019). Factors Effecting The Elasticity Of Micro Credit Demand In Southern Punjab, Pakistan. International Journal of Social Sciences and Economic Review, 1(2), 4653. doi: https://doi.org/10.36923/ijsser.v1i2.34

[37] Sarkar, U., Gourley, G. I., Lyles, C. R., Tieu, L., Clarity, C., Newmark, L., . . . Bates, D. W. (2016). Usability of commercially available mobile applications for diverse patients. Journal of general internal medicine, 31(12), 1417-1426.

[38] Sinha, N., \& Verma, P. (2018). The Role of Favoring and Inhibiting Factors in Developing Attitude towards Mobile Application based Agricultural Extension Services: A Structural Relationship. International Journal of Technology and Human Interaction (IJTHI), 14(4), 63-80.

[39] Sirgy, M. J. (1982). Self-concept in consumer behavior: A critical review. Journal of consumer research, 9(3), 287300.

[40] Taylor, S., \& Todd, P. A. (1995). Understanding information technology usage: A test of competing models. Information systems research, 6(2), 144176.
[41] Tseng, T.-H., \& Balabanis, G. (2017). The Role of "Consumer Need for Uniqueness" and Product Typicality in Explaining Variation of Country of Origin Effects The Customer is NOT Always Right? Marketing Orientationsin a Dynamic Business World (pp. 342-344): Springer.

[42] Tung, T., Koenig, H. F., \& Chen, H.-L. (2017). Effects of green self-identity and cognitive and affective involvement on patronage intention in eco-friendly apparel consumption: A gender comparison. Sustainability, 9(11), 1977.

[43] Ul-Hameed, W., Mohammad, H., \& Shahar, H. (2018). Microfinance institute's non-financial services and womenempowerment: The role of vulnerability. Management Science Letters, 8(10), 11031116. doi: https://doi.org/10.5267/j.msl.2018.7.001

[44] Wang, J., Cao, B., Yu, P., Sun, L., Bao, W., \& Zhu, X. (2018). Deep learning towards mobile applications. Paper presented at the 2018 IEEE 38th International Conference on Distributed Computing Systems (ICDCS).

[45] Wiedmann, K.-P., Hennigs, N., \& Siebels, A. (2007). Measuring consumers' luxury value perception: a cross-cultural framework. Academy of Marketing Science Review, 2007, 1.

[46] Wiedmann, K. P., Hennigs, N., \& Siebels, A. (2009). Value-based segmentation of luxury consumption behavior. Psychology \& Marketing, 26(7), 625-651.

[47] Workman, J. E., \& Kidd, L. K. (2000). Use of the need for uniqueness scale to characterize fashion consumer groups. Clothing and Textiles Research Journal, 18(4), 227-236.

[48] Xu, Q., Erman, J., Gerber, A., Mao, Z., Pang, J., \& Venkataraman, S. (2011). Identifying diverse usage behaviors of smartphone apps. Paper presented at the Proceedings of the 2011 ACM SIGCOMM 
conference on Internet measurement conference. 